\title{
Preventing Alcohol Consumption during Pregnancy: A Randomized Controlled Trial
}

\author{
Cristian Bortes*, Susanna Geidne, Charli Eriksson \\ School of Health and Medical Sciences, Örebro University, Örebro, Sweden \\ Email: ${ }^{*}$ criboh131@studentmail.oru.se
}

Received 31 January 2015; accepted 3 March 2015; published 10 March 2015

Copyright (C) 2015 by authors and Scientific Research Publishing Inc.

This work is licensed under the Creative Commons Attribution International License (CC BY). http://creativecommons.org/licenses/by/4.0/

(c) (i) Open Access

\section{Abstract}

The aim of this study is to report on a brief alcohol intervention for preventing drinking during pregnancy. The Women's Organizations Committee on Alcohol and Drug Issues (WOCAD) in Sweden developed an informational brochure about alcohol during pregnancy, intended to reach pregnant women before their first visit at a prenatal clinic. A randomized controlled trial was conducted between 2004 and 2005 to measure whether the brochure had any effect. A total of 564 pregnant women between 17 and 46 years of age are included in the study. Differences between the intervention and control groups were analyzed with cross-tabulations and chi-squared tests. A multiple logistic regression analysis was also conducted to determine predictors of abstention from alcohol at the first prenatal visit. Findings show that significantly more of the women who received the brochure abstained completely from alcohol then of those who did not receive it $(92 \%$ vs. $82 \%, p=0.005)$. It was 2.6 times more likely that those who received the brochure had abstained completely from alcohol since pregnancy recognition at their first prenatal visit compared with those who did not receive it $(O R=2.6$, CI $1.3-5.1, p=0.005)$. We conclude that the informational brochure developed by WOCAD can be used in prenatal care to get more women to abstain from alcohol during pregnancy.

\section{Keywords}

Pregnancy, Alcohol, Prevention, Sweden, Brief Intervention, Randomized Controlled Trial

\section{Introduction}

It is widely recognized that lifestyle during pregnancy, including diet and use of tobacco and alcohol, has a significant effect on the development and future health of the fetus [1] [2]. Prenatal alcohol exposure in particular

"Corresponding author. 
can be detrimental, leading to fetal alcohol spectrum disorders (FASD). Effects include brain damage, cognitive and behavioral impairment, and reduced quality of life [3] [4]. Despite its harmful influence, some women continue to consume alcohol during pregnancy.

Although FASD is completely preventable through alcohol abstinence during pregnancy, there is disagreement on how the patterns of exposure affect the child [5]. Heavy drinking is known to have a negative impact on the unborn child, but the impact of low to moderate alcohol consumption and binge drinking has been debated [6]. The amount, frequency, and timing of alcohol consumption during pregnancy, the degree to which consumption affects the fetus, and whether it leads to the child receiving a diagnosis within the FASD continuum, are all highly individual [7]. However, a recent meta-analysis of the association of mild, moderate, and binge prenatal alcohol exposure and child neuropsychological outcomes [8] failed to find evidence of any safe level of alcohol consumption during pregnancy. The best advice seemingly is to completely abstain from alcohol during pregnancy.

The prevalence of drinking during pregnancy varies between countries, as well as between urban and rural areas within countries [9] [10]. In Sweden, 6\% of pregnant women continue drinking during pregnancy [11] [12], in the United States 10\% [13], in Ireland 54\%, [14] and in Denmark 71\% [15]. Regardless of the differences in prevalence, alcohol consumption during pregnancy is a public health concern.

Turning to what can be done, most women in developed countries come in contact with some maternal health care service while pregnant. In Sweden, where maternal health care is free of charge, practically all pregnant women come to the public maternity care centers [12]. It is primarily in these settings that research and preventive efforts are performed. In order to detect hazardous drinking and identify pregnant women who are at-risk drinkers, midwives or other practitioners use alcohol-screening questionnaires such as the Michigan Alcoholism Screening Test (MAST) [16], T-ACE [17], and the Alcohol Use Disorder Identification Test (AUDIT) [18]-[20]. Women can be screened and offered to participate in an intervention when seeking emergency contraception or taking pregnancy tests at maternity clinics [21]. Improving effective contraception use among sexually active women in childbearing age is a further measure for preventing alcohol-exposed pregnancies [22] [23]. Different countries have different conditions in terms of health care settings and existing routines, and intervention-studies utilize those conditions in different ways.

A commonly used method for preventing alcohol-exposed pregnancies is motivational interviewing (MI) [24], a method that has been tested and evaluated [22] [25] [26]. MI interventions usually consist of several counseling sessions. Trials have also been performed to test single-session motivational interventions [27] [28]. These had less impact on alcohol-exposed pregnancy risk than interventions lasting four or more sessions, but it has been suggested that they can fill a gap in the continuum of alcohol-exposed pregnancy prevention, as they require less resources. Overall, MI interventions have proven to be effective in various settings at reducing alcohol-exposed risk, but they can be costly.

Other findings suggest more cost-effective alternatives to interventions delivered in-person. Brief interventions by telephone may be equally successful [29]. Web-based self-directed interventions [30] have also shown promising results, reducing alcohol consumption and increasing effective contraception use among both pregnant and non-pregnant women. However, these might be population-specific in terms of users' opportunities to use the telephone or the Internet and benefit from the interventions.

Other studies have worked with pre-conception interventions, targeting non-pregnant women with motivational interventions [27] [31] [32]. This research has demonstrated that motivational interventions can reduce the risk of alcohol-exposed pregnancies among women not yet pregnant but with high-risk criteria by giving them greater knowledge before pregnancy, leading to changed behavior to reduce adverse pregnancy outcomes.

It should, however, be pointed out that although the literature does include studies done in disadvantaged populations, the majority deal with communities of non-alcohol-dependent and non-treatment-seeking women. A success-factor related to this, as shown in studies, is that women have improved outcomes if they have a partner participating in the intervention process [33]. This relates to the concept of social capital, which suggests that social connectedness in itself has a positive effect on health status [34]. We also know that families and friends influence women's decision to drink or to abstain from alcohol [35] and that higher social support before pregnancy is associated with decreased risk of drinking during pregnancy [36].

Systematic reviews of interventions delivered during prenatal care suggest that there are examples of successful interventions, but their effectiveness varies overall [19] [33] [37]. The interventions reviewed comprise a total of 14 randomized controlled trials (RCTs) and 2 non-RCTs, and are so-called psycho-educational interven- 
tions such as brief interventions, supportive counseling, high feedback ultrasound, single to multi-motivational interviewing (MI) sessions, self-guided self-help manuals, and basic educational interventions. The conclusion one can draw regarding these studies is that they differ in terms of providing sufficient evidence. The studies lack statistical significance between control and intervention groups. They have problems of transferability and generalizability to other settings, as well as methodological weaknesses leading to risk of bias. These limitations suggest a need for further research.

Within the Swedish context, an evaluation comparing a new comprehensive questionnaire-based counseling model with standard maternity care [38] concluded that the new model was not more effective at getting women to abstain from drinking alcohol during pregnancy. This suggests that interventions are not necessarily better the more extensive they are. A small intervention procedure can be just as effective, taking all other resources into account. Hence, more efforts are needed to test brief interventions in a Swedish context.

\section{Context of the Study}

The aim of this study is to report on a brief alcohol intervention for preventing drinking during pregnancy, because it is relevant to filling some of the above-mentioned gaps. The study was conducted during 2004 and 2005 and has not yet been scientifically reported.

The Women's Organizations Committee on Alcohol and Drug Issues (WOCAD) is the Swedish women's organizations' coordinating body for matters concerning alcohol, illicit drugs, and addictive medications. The organization is free from political or religious affiliations. WOCAD works primarily with prevention activities, and their target group consists of girls and women of all ages.

Because studies showed that many women consume alcohol during the first three months of pregnancy [11] [39], WOCAD developed an informational brochure about alcohol during pregnancy, intended to reach pregnant women before their first visit at a prenatal clinic. This is because in Sweden, especially in larger cities, it can take about six weeks after a pregnant woman firsts contacts her prenatal clinic before she gets an appointment. There was also a prevailing view that women sometimes continue to drink during this time, as they do not reveal their pregnancy officially until their first prenatal visit. This makes it important to reach women as early as possible with prevention efforts.

A team of representatives from Karolinska Institutet, the Swedish Association of Midwives, Stockholm University, the staff of two maternity clinics, and WOCAD's member organizations developed the brochure, and it was distributed in March 2004 to a maternity clinic in Södermalm, Stockholm.

Did the brochure have any significant effect? Was there any difference between the intervention and control groups concerning abstaining from alcohol in the period leading up to the first prenatal visit? If so, what factors contributed to such abstention?

\section{Method}

To measure whether WOCAD's brochure on alcohol and pregnancy had an effect on pregnant women and their living habits, a research team from Örebro University conducted a randomized controlled study [40]. It was performed under the auspices of a research program financed by the Swedish National Board of Health and Welfare with the overall aim of evaluating non-governmental organizations' alcohol and drug preventive work [41].

\subsection{Data Collection}

One group of pregnant women received WOCAD's brochure by post in the same envelope as the notice for their first prenatal visit. The second group received the brochure from the midwife during their first prenatal visit. The midwives were randomly assigned to one of these procedures. The experiment conducted in Södermalm began June 15, 2004 and continued until February 21, 2005. During this time, 564 pregnant women were asked to respond to the survey and a total of 454 allowed the researchers to link their answers with their medical records.

The pregnant women were assigned to the intervention or control group according to which midwife they met. This was randomized, such that $37 \%$ of the women received the brochure at home before the visit, and $63 \%$ received it during the visit, after having completed a questionnaire in the waiting room. The groups are comparable for the background-variables age, previous children, and self-reported lifestyles. There is a significant difference in the variables employment and marital status (see Table 1). 
Table 1. Independent variables compared between control and intervention group (in \%) with chi-square tests.

\begin{tabular}{|c|c|c|c|c|c|}
\hline Background variables & & $\mathrm{N}$ & Control & Intervention & $p$-value \\
\hline \multirow[t]{3}{*}{ Age } & $<30$ & 177 & 40.9 & 35.9 & 0.538 \\
\hline & $31-33$ & 138 & 29 & 32.9 & \\
\hline & $>34$ & 138 & 30.1 & 31.1 & \\
\hline \multirow[t]{3}{*}{ Employment } & Full-time & 306 & 63.5 & 75.3 & 0.021 \\
\hline & Part-time & 64 & 15.1 & 12.7 & \\
\hline & Other & 81 & 21.4 & 12 & \\
\hline \multirow[t]{3}{*}{ Marital status } & Cohabiting with the child's father & 434 & 94.4 & 98.2 & 0.005 \\
\hline & Single & 2 & 0 & 1.2 & \\
\hline & Other family situation & 17 & 5.6 & 0.6 & \\
\hline \multirow[t]{3}{*}{ Previous children } & First child & 277 & 62 & 60.5 & 0.307 \\
\hline & Second child & 144 & 32.7 & 30.5 & \\
\hline & Third child or more & 30 & 5.3 & 9 & \\
\hline \multirow[t]{3}{*}{$\begin{array}{l}\text { Alcohol use } 3 \text { months prior to } \\
\text { current pregnancy }\end{array}$} & Rarely/never & 151 & 31.6 & 37.3 & 0.055 \\
\hline & Not more than 1 time/week & 200 & 48.9 & 37.3 & \\
\hline & None & 360 & 79.4 & 79.6 & \\
\hline \multirow[t]{3}{*}{$\begin{array}{l}\text { Tobacco use } 3 \text { months prior to } \\
\text { current pregnancy }\end{array}$} & 1 - 9 cigarettes/day & 45 & 8.4 & 12.6 & 0.225 \\
\hline & 10 cigarettes/day & 37 & 9.8 & 5.4 & \\
\hline & Snuff & 11 & 2.4 & 2.4 & \\
\hline
\end{tabular}

\subsection{Questionnaire}

When the women came to their first prenatal visit at the maternity center they answered a questionnaire in the waiting room. At this stage, one group of women $(n=167)$ had already received WOCAD's information brochure while the second group $(\mathrm{n}=287)$ had not received it. The questionnaire was based on the Transtheoretical model of behavior change [42]. It set out to measure the women's pre-contemplation, contemplation, and preparation for changing their lifestyle habits in different areas of their life. These areas were work-hours, diet, exercise, sleeping habits, and medications, as well as alcohol and tobacco abstention. The women were also asked if they had taken action to change any of the above since pregnancy recognition. The variables age, marital status, employment, and previous children were collected from their medical records. 454 (81\%) of the participants allowed the research team to link their responses with their medical records data, which was done by one person from the team.

\subsection{Sample Characteristics}

The pregnant women were between 17 and 46 years of age at the time of the visit, with a median age of 32 years. First-time mothers, comprising $62 \%$ of the respondents, had a median age of 30 years. The vast majority (96\%) were cohabiting with the child's father. Nearly $70 \%$ worked full-time, and nearly $20 \%$ worked part-time. Approximately $10 \%$ reported that they were students.

\subsection{Measures}

\subsubsection{Background Variables}

Age was measured by year of birth and categorized as $<30,31-33,>34$. Previous children had the options first child, second child, third child or more. Marital status had the options cohabiting with the child's father, single, other family situation. Employment had the options full-time, part-time, and other. Alcohol habits three months 
prior to the current pregnancy had the response options rarely/never, no more than once a week, more than once a week.

\subsubsection{Lifestyle Habits}

The measures for lifestyle are derived from the survey-question "Has your pregnancy caused you to change your lifestyle habits? Check the option that fits your situation. Several options are possible.” This is followed by the statement "Since pregnancy recognition I have..." to which the participant may agree by checking a box or leave it unchecked. The options for the participant to check are as follows: changed my work-hours, changed my eating habits, completely abstained from alcohol, completely abstained from smoking, changed my sleeping habits, changed my exercise habits, changed my medication habits.

\subsubsection{Alcohol Abstention}

The measure completely abstained from alcohol since pregnancy recognition is derived from the option completely abstained from alcohol. An unchecked box beside the option completely abstained from alcohol = No answer, and is interpreted as having been drinking a bit, any amount whatsoever.

\subsection{Data Analysis}

The SPSS software package version 22 was used for statistical analysis. Differences between the intervention and control groups were analyzed with cross-tabulations and chi-squaredtests. Background variables compared between groups are age, employment, maritalstatus, previous children, alcohol use three months prior to current pregnancy, and tobacco use three months prior to current pregnancy. The variables for lifestyle habits are medication habits, working hours, eating habits, sleeping habits, smoking abstention, exercise habits, and alcohol abstention. A multiple logistic regression analysis using the enter method was conducted to determine predictors of abstention from alcohol at the first prenatal visit. The dependent variable used in the analysis is complete alcohol abstention since pregnancy recognition at the first prenatal visit. The independent variables are the midwife routine(having received the brochure before the first prenatal visit) or the other routine (not having received it), alcohol use three months prior to current pregnancy, previous children, employment, marital status, and age. The regression model demonstrated good model fit according to Hosmer and Lemeshow's goodness-of-fit test $\left(\chi^{2}(8)=6.22, p=0.622\right)$. Results are reported as odds ratios, with $95 \%$ confidence intervals and $p$-values. All results were considered significant at $p \leq 0.05$.

\subsection{Ethics}

The study was conducted in accordance with the key requirements of good research ethics. The participants were informed about the purpose of the research through an information sheet when they arrived for their first visit at the maternity center. Participation in the survey was voluntary and they were able to provide informed consent. Participants were informed about the confidentiality of the data and how it would be used; specifically, they were told that only the research team would have access to the collected data, that it would be used solely for research purposes, and that no identifying information would remain accessible.

According to the Ethical Review Act of 2008 [43], all research with sensitive personal data must be ethically reviewed, regardless of how the data is collected and regardless of whether or not research participants give their consent. The current study contains sensitive personal data and would have to be reviewed by a research ethics board if performed today. However, because it was conducted before 2008, before the Ethical Review Act restrictions were imposed, it was not ethically reviewed. Moreover, a preexisting collaboration was in place between the prenatal clinic and one of the authors of the brochure, Mona Göransson, from a previous study she performed there [39].

\section{Results}

Significantly, more of the women who received the brochure had changed their alcohol habits since pregnancy recognition and were abstaining completely from alcohol at their first prenatal visit than did those who had not received the brochure $(92 \%$ vs. $82 \%, p=0.005)$ (Table 2$)$.

Predictive factors of abstention from alcohol since pregnancy recognition at the first prenatal visit used in the 
Table 2. Differences between control and intervention group (in \%) with chi-square tests.

\begin{tabular}{|c|c|c|c|c|}
\hline Lifestyle habits & $\mathrm{N}$ & Control & Intervention & $p$-value \\
\hline \multicolumn{5}{|l|}{ Since pregnancy recognition I have... } \\
\hline Changed my med. habits & 129 & 24.6 & 35.3 & 0.015 \\
\hline No & 322 & 75.4 & 64.7 & \\
\hline Changed my work hours & 35 & 14 & 21 & 0.003 \\
\hline No & 417 & 95.1 & 87.4 & \\
\hline Changed my eating habits & 248 & 54 & 56.3 & 0.642 \\
\hline No & 204 & 46 & 43.7 & \\
\hline Completely abstained from smoking & 287 & 60.2 & 69.5 & 0.049 \\
\hline No & 164 & 39.8 & 30.5 & \\
\hline Changed my sleeping habits & 156 & 29.8 & 42.5 & 0.006 \\
\hline No & 296 & 70.2 & 57.5 & \\
\hline Changed my exercise habits & 101 & 19.6 & 26.9 & 0.072 \\
\hline No & 351 & 80.4 & 73.1 & \\
\hline Completely abstained from alcohol & 387 & 82.1 & 91.6 & 0.005 \\
\hline No & 65 & 17.9 & 8.4 & \\
\hline
\end{tabular}

logistic regression model were age, marital status, employment, alcohol use three months prior to current pregnancy, previous children, and midwife routine (Table 3).

The factors that significantly contributed to abstention from alcohol since pregnancy recognition at the first prenatal visit were the midwife routine intervention group ( $\mathrm{OR}=2.6$, CI $1.3-5.1, p=0.005$ ), and alcohol use three months prior to current pregnancy. It was 2.6 times more likely for those who received the informational brochure to have abstained completely from alcohol since pregnancy recognition until their first prenatal visit than for those who did not receive it. Women who were already abstaining completely from alcohol at the first visit were 1.9 times more likely to have used alcohol no more than once a week prior to the current pregnancy compared to those who used it rarely/never ( $\mathrm{OR}=2.0$, CI $1.1-3.6, p=0.035)$.

Furthermore, women who were abstaining completely from alcohol at the first visit were 2.5 times more likely to have used alcohol once a week or more three months prior to their current pregnancy than those who used it rarely/never $(\mathrm{OR}=2.6$, CI $1.1-6.2, p=0.033)$.

\section{Discussion}

This study shows that it is possible to influence pregnant women early on during pregnancy with a rather small and simple intervention. One goal of the WOCAD's project was to get pregnant women to stop using alcohol during pregnancy. The brief intervention reported in this paper has been shown capable of doing so. It was found that significantly more women in the intervention group than the control group also changed their lifestyle habits in other areas of life (Table 2). The message of the brochure, that pregnancy is not a time to take chances, seems to have got through.

One thing worth mentioning is that many women in the control group were also abstaining completely from alcohol at their first prenatal visit, although not as many. We know that parents change their lifestyle habits at pregnancy recognition to ensure the health of the fetus [44]. Pregnancy is a window of opportunity through which health-promoting interventions can be applied, since parents are generally open to change at that time.

The logistic regression model shows that women who used alcohol prior to the current pregnancy were influenced by the intervention to a higher degree. It seems they changed to a greater extent than those who rarely or never used alcohol three months prior to the current pregnancy. One interpretation of this is that women who 
Table 3. Multiple logistic regression (enter method) for completely abstaining from alcohol since pregnancy regocnition at the first prenatal visit.

\begin{tabular}{|c|c|c|c|c|}
\hline Predictors & $\operatorname{Exp}(B)$ & 95\% C.I. for EXP(B) & & $p$-value \\
\hline & & Lower & Upper & \\
\hline \multicolumn{5}{|l|}{ Midwife routine } \\
\hline Control & 1.0 & & & \\
\hline Intervention & 2.63 & 1.34 & 5.14 & 0.005 \\
\hline \multicolumn{5}{|l|}{ Alcohol use 3 months before } \\
\hline Rarely/never & 1.0 & & & \\
\hline No more than once a week & 1.96 & 1.05 & 3.61 & 0.035 \\
\hline More than once a week & 2.59 & 1.08 & 6.19 & 0.033 \\
\hline \multicolumn{5}{|l|}{ Previous children } \\
\hline First & 1.07 & 0.32 & 3.55 & 0.905 \\
\hline Second & 0.96 & 0.31 & 3.01 & 0.952 \\
\hline Third or more & 1.0 & & & \\
\hline \multicolumn{5}{|l|}{ Employment } \\
\hline Full-time & 1.74 & 0.87 & 3.47 & 0.114 \\
\hline Part-time & 2.27 & 0.86 & 6.00 & 0.094 \\
\hline Other & 1.0 & & & \\
\hline \multicolumn{5}{|l|}{ Marital status } \\
\hline Cohabiting with child's father & 1.0 & & & \\
\hline Single & 0.06 & 0.00 & 1.16 & 0.063 \\
\hline Other & 3.6 & 0.45 & 29.59 & 0.227 \\
\hline \multicolumn{5}{|l|}{ Age } \\
\hline$<30$ & 0.81 & 0.40 & 1.66 & 0.578 \\
\hline $31-33$ & 1.5 & 0.69 & 3.28 & 0.303 \\
\hline$>34$ & 1.0 & & & \\
\hline
\end{tabular}

1.0 denotes reference category.

drank occasionally, once a week or more, got more to think about after receiving the brochure. They thus changed their drinking behavior more because they had more of it to change. Women who rarely or never drank alcohol had little or nothing to change.

This result challenges findings from several studies [36] [45]-[47], including a systematic review [48] showing that predictors most positively associated with alcohol use during pregnancy are pre-pregnancy alcohol consumption, higher maternal age, and previous children. The argument is that behavioral patterns established prior to pregnancy are difficult to alter, and more difficult the longer they have been present [11]. According to this, the women in our study who scored higher for alcohol use three months prior to the current pregnancy would be more difficult to influence. In contrast, in our regression analysis these women showed the greatest change and the intervention had the greatest influence on them. However, this interpretation may be less accurate.

\subsection{Limitations and Strengths}

We know that lifestyle habits, such as alcohol consumption, differ between populations in different regions. 
Women in larger cities drink as a social activity more than women in smaller towns [10] [36]. The study sample is from a city district of Stockholm where the availability of alcohol is high. This needs to be taken into account when considering the generalizability and external validity of the study findings.

There are also other explanations of the change occurring in both groups. We need to take possible screening effects into consideration. This means that significant measurable differences in drinking behavior can be created just by asking women about their drinking habits [49]. This could also apply to other lifestyle habits asked about in the questionnaire. The responses of women in both groups are likely to have been affected bytheir having answered the questionnaire on lifestyle habits distributed by the midwife at their first prenatal visit.

A remark must be made regarding the imprecision of the measure completely abstained from alcohol since pregnancy recognition: The only options on the survey were to check "completely abstained," or to leave the box empty. We assume that leaving it empty meant the participant had not completely abstained from alcohol since pregnancy recognition. A more precise measure would give more response options regarding the frequency and quantity of alcohol consumption since pregnancy recognition. But then again, we know that pregnant women tend to deny or underreport alcohol consumption [50]. In our case we lose some precision but capture the core of either completely abstaining or not. Also, concerns about recall bias might be raised, since the participants were asked to assess their alcohol use three months prior to current pregnancy. Still, compared to the common practice of asking for previous alcohol consumption one year preceding current pregnancy, in order to avoid misreporting due to the social stigma associated with drinking and pregnancy, three months is not that far back. A final remark concerns a possible carry-over effect, as the difference between groups for the background variable alcohol use three months before pregnancy was close to significant (see Table 1). Moreover, it was not feasible to use any biological indicator for alcohol consumption in this study.

Despite these limitations there are several strengths in this study. One is the large sample size. Another is the random assignment of participants into control and intervention groups. With the exception of the background variables employment and marital status the groups are similar. This makes us confident that the changes are due to the intervention and not the characteristics of the group. Furthermore, the prenatal clinic at which the study was conducted was accustomed to handling scientific studies. This facilitated the process.

\subsection{Future Research}

During data collection, we gained access to AUDIT-scores from some of the participating women. A potential research question could be whether those who scored for hazardous drinking were abstaining completely from alcohol at their first prenatal visit or not, and to look for comparisons between the intervention and control groups. This could have been an interesting question to measure, because non-risk drinkers might have abstained from alcohol to a greater extent with or without the intervention. However, there was some missing data because the midwives were inconsistent in doing AUDIT screenings, and an insufficient number of women with AUDIT-scores reported hazardous drinking for us to do the measurement (which in itself is a good thing).

The success of an intervention like this, reaching out to newly pregnant women at an early phase to prevent alcohol-exposure during the early critical weeks, owes much to the conditions in a country's healthcare system. In countries where the maternity care is unlike that in Sweden, outreach programs may be needed to find women and prevent adverse pregnancy outcomes. Evaluations of this approach when implemented in other maternal health services in Sweden would be valuable. The program will also be introduced in Eastern Europe, where alcohol consumption among women is much higher than in Sweden.

Midwives across Sweden have helped with the dissemination of the brochure, but how has it been incorporated into existing routines? Several counties have the policy to use the AUDIT questionnaire in order to screen for risky drinking, and in 2009 the Swedish Public Health Agency issued "The midwife's guide for conversations about alcohol" [51]. But what approach do Swedish prenatal clinics have today and how uniform are the practices on alcohol issues? This is a question of fairness and equality, and could be a topic for future study.

\section{Conclusion}

In contrast to previous research on information initiatives, which finds that they have little effect on people's alcohol consumption, the use of WOCAD's brochure has proven to have a significant effect. Furthermore, it requires little resources, is easy to manage, and can function as a complement to standard practice in prenatal care to get more women to abstain from alcohol during pregnancy. 


\section{Acknowledgements}

This study is part of Cristian Bortes’ master's thesis in Public Health Science with a focus on prevention. Susanna Geidne, PhD, is his supervisor. Professor Charli Eriksson, Örebro University, is the recipient of a grant from the National Board of Health and Welfare for the research program. The authors wish to thank the Women's Organizations Committee on Alcohol and Drug Issues in Sweden, the participating maternity clinic and its personnel, and all the pregnant women who participated.

\section{References}

[1] Mcknight, K.K. (2013) Science-Based Answers to Prenatal Lifestyle Questions. Contemporary OB/GYN, 58, 20-32.

[2] Kesmodel, U.S., Underbjerg, M., Kilburn, T.R., Bakketeig, L., Mortensen, E.L., Landro, N.I., Schendel, D. and Thorsen, P. (2010) Lifestyle during Pregnancy: Neurodevelopmental Effects at 5 Years of Age. The Design and Implementation of a Prospective Follow-Up Study. Scandinavian Journal of Public Health, 38, 208-219. http://dx.doi.org/10.1177/1403494809357093

[3] Petrenko, C.L.M. and Riley, E.P. (2010) The Effects of Prenatal Alcohol Exposure on Brain and Behavior. In: Preece, P.M. and Riley, E.P., Eds., Alcohol, Drugs and Medication in Pregnancy: The Long-Term Outcome for the Child, Mac Keith Press, London, 108-129.

[4] Barrow, M. and Riley, E.P. (2010) Diagnosis of Fetal Alcohol Syndrome: Emphasis on Early Detection. In: Preece, P.M. and Riley, E.P., Eds., Alcohol, Drugs and Medication in Pregnancy: The Long-Term Outcome for the Child, Mac Keith Press, London, 85-107.

[5] Gray, R. (2010) Epidemiology of Drug and Alcohol Use during Pregnancy. In: Preece, P.M. and Riley, E.P., Eds., Alcohol, Drugs and Medication in Pregnancy: The Long-Term Outcome for the Child, Mac Keith Press, London, 11-22.

[6] Meyer-Leu, Y., Lemola, S., Daeppen, J.-B., Deriaz, O. and Gerber, S. (2011) Association of Moderate Alcohol Use and Binge Drinking during Pregnancy with Neonatal Health. Alcoholism: Clinical and Experimental Health, 35, 16691677. http://dx.doi.org/10.1111/j.1530-0277.2011.01513.x

[7] May, P.A., Blankenship, J., Marais, A-S., Gossage, J.P., Kalberg, W.O., Joubert, B., Cloete, M. and Barnard Seedat, S. (2013) Maternal Alcohol Consumption Producing Fetal Alcohol Spectrum Disorders (FASD): Quantity, Frequency, and Timing of Drinking. Drug and Alcohol Dependence, 133, 502-512. http://dx.doi.org/10.1016/j.drugalcdep.2013.07.013

[8] Flak, A.L., Su, S., Bertrand, J., Denny, C.J., Kesmodel, U.S. and Cogswell, M.E. (2014) Association of Mild, Moderate, and Binge Prenatal Alcohol Exposure and Child Neuropsychological Outcomes: A Meta-Analysis. Alcoholism: Clinical and Experimental Research, 38, 214-226. http://dx.doi.org/10.1111/acer.12214

[9] Balachova, T., Bonner, B., Chaffin, M., Bard, D., Isurina, G., Tsvetkova, L. and Volkova, E. (2012) Women's Alcohol Consumption and Risk for Alcohol-Exposed Pregnancies in Russia. Addiction, 107, 109-117. http://dx.doi.org/10.1111/j.1360-0443.2011.03569.x

[10] Hensing, G. (2012) The Health Consequences of Alcohol and Drug Abuse: Health in Sweden: The National Public Health Report 2012. Scandinavian Journal of Public Health, 40, 211-228. http://dx.doi.org/10.1177/1403494812459608

[11] Göransson, M., Magnusson, Å., Bergman, H., Rydberg, U. and Heilig, M. (2003) Fetus at Risk: Prevalence of Alcohol Consumption during Pregnancy Estimated with a Simple Screening Method in Swedish Antenatal Clinics. Addiction, 98, 1513-1520. http://dx.doi.org/10.1046/j.1360-0443.2003.00498.x

[12] Nilsen, P., Holmqvist, M., Hultgren, E., Bendtsen, P. and Cedergren, M. (2008) Alcohol Use before and during Pregnancy and Factors Influencing Change among Swedish Women. Acta Obstetricia et Gynecologica Scandinavica, 87, 768-774. http://dx.doi.org/10.1080/00016340802179830

[13] Tsai, J. and Floyd, R.L. (2004) Alcohol Consumption among Women Who Are Pregnant or Who Might Become Pregnant-United States, 2002. MMWR: Morbidity and Mortality Weekly Report, 53, 1178-1181.

[14] Donnelly, J., Cooley, S., Walsh, T., Sarkar, R., Durnea, U. and Geary, M. (2008) Illegal Drug Use, Smoking and Alcohol Consumption in a Low-Risk Irish Primigravid Population. Journal of Perinatal Medicine, 36, 70-72. http://dx.doi.org/10.1515/JPM.2008.006

[15] Kesmodel, U.S., Kesmodel, P., Larsen, A. and Secher, N. (2003) Use of Alcohol and Illicit Drugs among Pregnant Danish Women. Scandinavian Journal of Public Health, 31, 5-11. http://dx.doi.org/10.1080/14034940210134202

[16] Selzer, M.L. (1971) The Michigan Alcoholism Screening Test: The Quest for a New Diagnostic Instrument. American Journal of Psychiatry, 127, 1653-1658. http://dx.doi.org/10.1176/ajp.127.12.1653

[17] Sokol, R.J., Martier, S.S. and Ager, J.W. (1989) The T-ACE Questions: Practical Prenatal Detection of Risk-Drinking. 
American Journal of Obstetrics and Gynecology, 160, 863-871. http://dx.doi.org/10.1016/0002-9378(89)90302-5

[18] Babor, T.F., Higgins-Biddle, J.C., Saunders, J.B. and Monteiro, M.G. (2001) The Alcohol Use Disorders Identifications Test. Guidelines for Use in Primary Care. 2nd Edition, World Health Organization, Geneva.

[19] Nilsen, P. (2009) Brief Alcohol Intervention to Prevent Drinking during Pregnancy: An Overview of Research Findings. Current Opinion in Obstetrics \& Gynecology, 21, 496-500. http://dx.doi.org/10.1097/GCO.0b013e328332a74c

[20] Holmqvist, M. and Nilsen, P. (2010) Approaches to Assessment of Alcohol Intake during Pregnancy in Swedish Maternity Care-A National-Based Investigation into Midwives’ Alcohol-Related Education, Knowledge and Practice. Midwifery, 26, 430-434. http://dx.doi.org/10.1016/j.midw.2008.10.009

[21] Walker, D.S., Fisher, C.S.D., Sherman, A., Wybrecht, B. and Kyndely, K. (2005) Fetal Alcohol Spectrum Disorders Prevention: An Exploratory Study of Women's Use of, Attitudes towards, and Knowledge about Alcohol. Journal of the American Academy of Nurse Practitioners, 17, 187-193. http://dx.doi.org/10.1111/j.1745-7599.2005.0031.x

[22] Rendall-Mkosi, K., Morojele, N., London, L., Moodley, S., Singh, C. and Girdler-Brown, B. (2013) A Randomized Controlled Trial of Motivational Interviewing to Prevent Risk for an Alcohol-Exposed Pregnancy in the Western Cape, South Africa. Addiction, 108, 725-732. http://dx.doi.org/10.1111/add.12081

[23] Fabbri, S., Farrell, L.V., Penberthy, J.K., Ceperich, S.D. and Ingersoll, K.S. (2009) Toward Prevention of Alcohol Exposed Pregnancies: Characteristics that Relate to Ineffective Contraception and Risky Driving. Journal of Behavioral Medicine, 32, 443-452. http://dx.doi.org/10.1007/s10865-009-9215-6

[24] Miller, W. and Rollnick, S. (2012) Motivational Interviewing: Helping People Change. 3rd Edition, Guilford, London.

[25] Osterman, R.L. (2011) Decreasing Women’s Alcohol Use during Pregnancy. Alcoholism Treatment Quarterly, 29, 436-452. http://dx.doi.org/10.1080/07347324.2011.608589

[26] Osterman, R.L. (2011) Feasibility of Using Motivational Interviewing to Decrease Alcohol Consumption during Pregnancy. Journal of Addictions Nursing, 22, 93-102. http://dx.doi.org/10.3109/10884602.2011.585723

[27] Ingersoll, K.S., Ceperich, S.D., Hettema, J.E., Farell-Carnhan, L. and Penberthy, K. (2013) Preconceptional Motivational Interviewing Interventions to Reduce Alcohol-Exposed Pregnancy Risk. Journal of Substance Abuse Treatment, 44, 407-416. http://dx.doi.org/10.1016/j.jsat.2012.10.001

[28] Osterman, R.L. and Dyehouse, J. (2011) Effects of a Motivational Interviewing Intervention to Decrease Prenatal Alcohol Use. Western Journal of Nursing Research, 34, 434-454. http://dx.doi.org/10.1177/0193945911402523

[29] Wilton, G., Moberg, D.P., Van Stelle, K.R., Dold, L.L., Obmascher, K. and Goodrich, J. (2013) A Randomized Trial Comparing Telephone versus In-Person Brief Intervention to Reduce the Risk of an Alcohol-Exposed Pregnancy. Journal of Substance Abuse Treatment, 45, 389-394. http://dx.doi.org/10.1016/j.jsat.2013.06.006

[30] Tenkku, L.E., Mengel, M.B., Nicholson, R.A., Hile, M.G., Morris, D.S. and Salas, J. (2011) A Web-Based Intervention to Reduce Alcohol-Exposed Pregnancies in the Community. Health Education \& Behavior, 38, 563-573. http://dx.doi.org/10.1177/1090198110385773

[31] Elsinga, J., de Jong-Potjer, L.C., van der Pal-de Bruin, K.M., le Cessie, S., Assendelft, W.J.J. and Buitendijk, S.E. (2008) The Effect of Preconception Counseling on Lifestyle and Other Behavior before and during Pregnancy. Women's Health Issues, 18, S117-S125.

[32] Floyd, R.L., Sobell, M., Velasquez, M.M., Ingersoll, K., Nettleman, M., Sobell, L. and Nagaraja, J. (2007) Preventing Alcohol-Exposed Pregnancies: A Randomized Controlled Trial. American Journal of Preventive Medicine, 32, 1-10. http://dx.doi.org/10.1016/j.amepre.2006.08.028

[33] Gilinsky, A., Swansson, V. and Power, K. (2011) Interventions Delivered during Antenatal Care to Reduce Alcohol Consumption during Pregnancy: A Systematic Review. Addiction Research \& Theory, 19, 235-250. http://dx.doi.org/10.3109/16066359.2010.507894

[34] Green, J. and Tones, K. (2010) Health Promotion: Planning and Strategies. 2nd Edition, Sage Publications, London.

[35] Elek, E., Harris, S.L., Squire, C.M., Margolis, M., Weber, M.K., Parra Dang, E. and Mitchell, B. (2013) Women’s Knowledge, Views, and Experiences Regarding Alcohol Use and Pregnancy: Opportunities to Improve Health Messages. American Journal of Health Education, 44, 177-190. http://dx.doi.org/10.1080/19325037.2013.768906

[36] Skagerström, J., Alehagen, S., Häggström-Nordin, E., Årestedt, K. and Nilsen, P. (2013) Prevalence of Alcohol Use before and during Pregnancy and Predictors of Drinking during Pregnancy: A Cross Sectional Study in Sweden. BMC Public Health, 13, 780. http://dx.doi.org/10.1186/1471-2458-13-780

[37] Stade, B.C., Bailey, C., Dzendoletas, D., Sgro, M., Dowswell, T. and Bennet, D. (2009) Psychological and/or Educational Interventions for Reducing Alcohol Consumption in Pregnant Women and Women Planning Pregnancy. Cochrane Database of Systematic Reviews, Article ID: CD004228. http://dx.doi.org/10.1002/14651858.CD004228.pub2

[38] Nilsen, P., Holmqvist, M., Bendtsen, P., Hultgren, E. and Cedergren, M. (2010) Is Questionnaire-Based Alcohol Counseling More Effective for Pregnant Women than Standard Maternity Care? Journal of Women's Health, 19, 161- 
167. http://dx.doi.org/10.1089/jwh.2009.1417

[39] Göransson, M. (2004) Alcohol Consumption during Pregnancy: How Do We Separate Myth from Reality? Doctorial Dissertation, Karolinska Institutet, Stockholm.

[40] Eriksson, C., Geidne, S., Larsson, M. and Pettersson, C. (2010) Med kraft och vilja. Alkohol och drogförebyggande arbete inom Socialstyrelsens stöd till frivilligorganisationer 2003-2009. Studier i folkhälsovetenskap, Örebro Universitet, Örebro, 1.

[41] Eriksson, C., Geidne, S., Larsson, M. and Pettersson, C. (2011) A Research Strategy Case Study of Alcohol and Drug Prevention by Non-Governmental Organizations in Sweden 2003-2009. Substance Abuse Treatment, Prevention, and Policy, 6, 8. http://dx.doi.org/10.1186/1747-597X-6-8

[42] Prochaska, J.O. and DiClemente, C.C. (1984) The Transtheoretical Approach: Towards a Systematic Eclectic Framework. Dow Jones Irwin, Homewood.

[43] Swedish Government Bill (2007) Vissa etikprövningsfrågor m.m. Ministry of Education and Research, Stockholm.

[44] Edvardsson, K., Ivarsson, A., Eurenius, E., Garvare, R., Nyström, M.E., Small, R. and Mogren, I. (2011) Giving Offspring a Healthy Start: Parents' Experiences of Health Promotion and Lifestyle Change during Pregnancy and Early Parenthood. BMC Public Health, 11, 936. http://dx.doi.org/10.1186/1471-2458-11-936

[45] Hutchinson, D., Moore, E.A., Breen, C., Burns, L. and Mattick, R.P. (2013) Alcohol Use in Pregnancy: Prevalence and Predictors in the Longitudinal Study of Australian Children. Drug and Alcohol Review, 32, 475-482.

[46] Powers, J., McDermott, L., Loxton, D. and Chojenta, C. (2013) A Prospective Study of Prevalence and Predictors of Concurrent Alcohol and Tobacco Use during Pregnancy. Maternal and Child Health Journal, 17, 76-84. http://dx.doi.org/10.1007/s10995-012-0949-3

[47] Comasco, E., Hallberg, G., Helander, A., Oreland, L. and Sundelin-Wahlsten, V. (2012) Alcohol Consumption among Pregnant Women in a Swedish Sample and Its Effects on the Newborn Outcomes. Alcoholism: Clinical and Experimental Research, 36, 1779-1786. http://dx.doi.org/10.1111/j.1530-0277.2012.01783.x

[48] Skagerström, J., Chang, G. and Nilsen, P. (2011) Predictors of Drinking during Pregnancy: A Systematic Review. Journal of Women's Health, 20, 901-913. http://dx.doi.org/10.1089/jwh.2010.2216

[49] Parkes, T., Poole, N., Salmon, A., Greaves, L. and Urquhart, C. (2008) Double Exposure: A Better Practices Review on Alcohol Interventions during Pregnancy. British Columbia Centre of Excellence for Women's Health, Vancouver.

[50] Alvik, A., Haldorsen, T., Groholt, B. and Lindemann, R. (2006) Alcohol Consumption before and during Pregnancy Comparing Concurrent and Retrospective Reports. Alcoholism: Clinical and Experimental Research, 30, 510-515. http://dx.doi.org/10.1111/j.1530-0277.2006.00055.x

[51] Carlén, C., Johansson, A., Lundblad, E. and Envall, E.K. (2009) Barnmorskans guide för samtal om alkohol. Statens Folkhälsoinstitut, Östersund. 